\title{
Management System for Multidisciplinary University Research Institutes
}

\author{
Simon P Philbin PhD MBA \\ Programme Director, Institute of Shock Physics \& Visiting Fellow, Business School \\ Imperial College London \\ Royal School of Mines Building, South Kensington, \\ London SW7 2AZ, United Kingdom \\ Tel +44 207594 8605; Email s.philbin@imperial.ac.uk
}

\begin{abstract}
This paper focuses on multidisciplinary university research institutes and the management challenges that arise in developing and sustaining such institutes. The role of academic institutes is important, they bring together faculty to work on a specific scientific area, which can address a societal or commercial requirement. There are, however, certain issues with this approach, such as the need for effective research co-ordination; the importance of adequate governance mechanisms for managing across disciplines; and in the case of industry supported institutes the need to ensure academic outputs are properly aligned to industrial needs. In this context and through building on the literature on multidisciplinary institutes, a conceptual model has been generated for the development and management of institutes. This institute management system includes a process based on four main stages (design, initiate, deliver and sustain) as well as a set of governance themes. The management system has been applied to the Institute of Shock Physics at Imperial College London in the United Kingdom as part of a case study investigation. Subsequent analysis of the case study findings highlighted how the institute management system provides a broad-based and rigorous methodology to help establish new institutes and then ensure sustainable operations are achieved thereafter. Interpretation of the case study analysis emphasizes the role of the institute's leadership and faculty members in boundary spanning across disciplines and different organizations, and how social capital can be an important ingredient to facilitate this process. Moreover, in the case of industrial partners, their associated absorptive capacity is seen as an important enabler for ensuring companies that collaborate with university institutes have the required structures, processes and supporting culture to enable knowledge to be acquired and then deployed to advance companies' R\&D capabilities.
\end{abstract}

\section{Introduction}

Over the last couple of decades there has been a significant increase in the number of multidisciplinary university research institutes or centers, which have been largely created in order to address a specific requirement for research that draws on multiple academic subjects [1]. Such an arrangement differs from the historical organization of research in universities according to traditional academic disciplines, such as materials science, mechanical engineering, chemical engineering, geography, and so on. Research-intensive universities have been able to establish institutes as a mechanism to deliver research and in some cases also education in emerging multidisciplinary areas, such as in nanotechnology, biomedical engineering, systems biology, cybernetics, climate change science, and forensics. Development of these science and technology areas will either be driven by a societal need that is translated into a national or international funding requirement administered by a governmental or charitable organization, or alternatively will likely be driven by a commercial or industrial requirement. Either way, there will need to be a major stimulus that gives rise to the requirement for a multidisciplinary research institute to be established at a university or other organization such as a hospital.

Despite the growth in the number of research institutes to address multidisciplinary research and technology requirements, there are unfortunately a number of challenges that can be associated with managing such initiatives. In this regard, Bozeman and Boardman [2] have articulated a number of issues in the management of multidisciplinary institutes. They found that there can be an increased emphasis on research co-ordination within institutes, as opposed to within traditional academic departments where research management can be widely decentralized and faculty are free to pursue their own research agendas. Consequently, in order to achieve this co-ordination, the necessary structures and processes that operate within the institute need to be designed appropriately. They also found that there is a need for robust reporting lines for the leadership and governance arrangements for the institute as well as the importance of building collaborative networks both within institutes and externally.

Whilst institutes provide an ideal mechanism to deliver multidisciplinary research, there needs to be effective translation of knowledge generated in order to provide benefits to the primary funding organization(s), which could be industrial companies or governmental laboratories, and this can be encapsulated within the open innovation paradigm [3]. In the case of industrial companies, they may have partnered with a university institute in order to gain access to the latest scientific thinking or technologies to incorporate into products or services produced by the company, which can be related to the absorptive capacity of the company [4]

Alternatively, the company may be keen to have a close relationship with the institute in order to exploit any arising intellectual property, through a licensing or technology transfer arrangement. From the perspective of the university itself, bringing together faculty into a new institute can facilitate a new funding stream and help the university to strengthen its financial position. The faculty themselves will need to be motivated and sufficiently interested in developing their careers in the particular multidisciplinary field and in 
order to do this, they will need to be confident enough that their research results can be published in journals of an appropriate standing, i.e. those that will help underpin their case for tenure or equivalent. Indeed Speier and Palmer [5] found there can be a struggle in research centers between balancing the requirement for problem-driven or industrial focused research within a center against an academic's need to be published in journals and conference proceedings.

It is recognized that there are a range of different types of institutes at universities and sometimes they may be called research centers. Moreover, the range of organizational types will have different structures and processes that are contingent on the environment within which the institute or center is operating as well as its history. Nevertheless and for simplicity, in this paper, institutes and research centers will be regarded as being broadly equivalent.

This paper has been written in order to explore the merits of multidisciplinary university research institutes and to identify the underpinning structures and processes that contribute to an institute's success. Consequently, following on from a literature review in this area, a conceptual management model will be proposed that builds on findings from the literature and can be used as a framework for developing and managing institutes. The resulting institute management system will then be applied through a case study investigation of a university institute in the United Kingdom. The findings of the application will be evaluated through an underpinning management framework as part of an 'analysis lens' and then followed by concluding remarks.

\section{Multidisciplinary Research Institutes}

Multidisciplinary research institutes that are based within academic institutions need to deliver stakeholder value if they are to address the scientific and technology needs of government or industry and consequently be an integral part of the innovation system [6]. Moreover, ensuring that institutes have the required staff, facilities, organizational structures and supporting management processes in place is of fundamental importance in order to facilitate knowledge generation and subsequent knowledge capture by the funding organization. In the case of high-tech and industrial companies that have their own R\&D (research and development) bases, from sectors such as the pharmaceutical, chemicals, aerospace and defense, manufacturing and general engineering, this acquired knowledge will need to contribute to an advancement of the company's R\&D capabilities.

Moreover, at the firm level, there will likely be a specific driver for a company to associate with a university institute or center. Indeed Santoro and Chakrabarti [7] found that firms can have different motivations for establishing links with a university center. In some cases, the company will be attracted to a prestigious institution so that the firm can gain access to a particular inter-organizational network. Conversely, other companies may be more interested in gaining academic input to solve a technical problem and hence these companies may be more interested in building links with institutions that focus on applied research. The implications of this study are that a firms' involvement with any given university institute or center will be an extension of the companies' strategic objectives. Therefore, universities need to be aware of these objectives and crucially be able to act on such industrial strategies if they are to optimize their ability to gain industrial funding and support.

Liyanage and Mitchell [8] have explored Cooperative Research Centres (CRCs) in Australian universities. This study identified three main types of CRCs. There is a 'corporate type', which adopt business management practice and undertake more industrially aligned activities, such as research commercialization. A 'research type', where there was a major emphasis on individual faculty that had a high degree of autonomy as well as management being geared to delivering research goals. Plus an 'integrated type', where there is an equal emphasis on research, education and commercial functions, and there is a distinct focus on networking and communication between different functional areas associated with the centre. The study also described in detail the power structures that can exist in centers, such as a board of management and associated governance arrangements, and the corresponding organizational culture that can impact on the decision-making process. This research points to the need for the management structures and processes that underpin research institutes and centers to be designed in order to meet the institutes' objectives in terms of the balance between research, teaching and commercialization. Moreover, such a design should include the specification of governance arrangements and decisionmaking processes that will support these objectives.

Indeed government organizations are increasingly requiring universities to demonstrate the industrial applicability of research [9] and correspondingly there has been an increased emphasis on the commercial value that can be attached to knowledge generated at universities, e.g. through licensing of intellectual property (IP) or the formation of 'spin-out' companies [10]. In relation to IP management, Young et al [11] have studied the IP strategies adopted by publicly funded $R \& D$ centers at both universities and companies. They found that understandably university institutes are concerned with knowledge generation, but there is nevertheless a need for improved IP management frameworks in order to protect the intellectual assets and especially for institutes. The need for institutes to develop their own IP strategies that accommodate the respective policy-makers' viewpoints is also encouraged.

Establishing a new institute or center will involve the appointment of key academic staff as well as crucially ensuring there is strong leadership that will drive forward the development of the institute's resource base and establish the research and teaching agenda. In regard to the management of research centers, Bozeman and Boardman [2] have pointed to the need for center directors to take the lead on technical strategy and managing relations with external funding sources, whilst administrative directors take the lead on managing the internal operations of the centers. They point to the advantages from a clear distinction between these roles, which helps to ensure there is clarity over responsibilities in terms of project delivery as well as reporting arrangements with any funding organizations. 
Once the basis for a new multidisciplinary institute has been agreed upon and there is a clear scientific direction, the design of the institute will then be emerging in terms of the required structures and processes to meet the stakeholder needs and address the corresponding scientific requirements. Following on from the design, it can therefore be elucidated that there is a need to formally initiate or start-up the institute. This stage will likely involve the formulation and approval of the financial and contractual arrangements that underpin the institute, including the award of supporting funds and allocation of monies to the institute. As mentioned previously, the applicability of any institute specific IP conditions will also need to be considered.

Ensuring the institute has the main leadership positions in place is also a necessary part of this stage, as the founding leaders of any institute will be required to invest a significant amount of their own personal capital (or credibility) into the institute as well as a major contribution in time and effort. Moreover, ensuring that the leadership team has the requisite enthusiasm and gravitas, and in the case of faculty, the required scientific and technical expertise, is therefore of fundamental importance to the initiation of a new institute. Where appropriate, there will also need to be appropriate plans in place for the appointment of additional academic and research staff as well as students (e.g. at the MSc or $\mathrm{PhD}$ level) in order to deliver the research outputs of the institute.

After an institute has been initiated, there is a need to deliver the research and any teaching activities. On this matter, Youtie and Corley [12] have studied how organizational learning within centers can be impeded by a lack of stability in management structures and processes as well as instability with the research agenda. Ensuring there is a defined management system operating across research institutes and which accommodates broader considerations is therefore encouraged, including oversight of management, operations, safety, facilities, research and technology, teaching and outreach. During the delivery period, progress should be monitored and controlled to ensure advancement across all of these areas and that the overall learning process is supported. Involvement of faculty with institute operations and especially where there is industrial support of research has been viewed in terms of both "scientific and technical human capital" [13]. In this context and in order to ensure there are productive collaborations within industry supported institutes there should be arrangements to facilitate boundary spanning [14] across the institute's main discipline areas and organizational interfaces. There should also be alignment of faculty's goals with those of the institutes.

Delivery of high quality academic outputs that meet stakeholder requirements is essential but in order to ensure the long-term development of multidisciplinary institutes, there also needs to be an adequate focus on sustainability and longterm funding. Indeed Feller et al. [15] has highlighted the difficulties encountered by US National Science Foundation (NSF) engineering research centers in attempting to gain follow-on funding beyond the initial NSF investment program. The need to develop a supporting business case that integrates the technical proposition of the institute with potential and available sources of external funding can be viewed as an important component in the sustainability of institutes. Moreover, this business case may need to change over time in order to mirror the advancement of the scientific agenda within the institute and also to respond to emerging needs from funding organizations.

Through building on research from the literature described previously, it is possible to conceptualize the development and management of multidisciplinary institutes in terms of an integrated institute management system (see Figure 1). The proposed system is composed of a four-stage management process and a set of underpinning governance themes. The four-stage process includes a development phase (the design and initiate stages) and a management cycle (the deliver and sustain stages). It is postulated that the development of institutes will be undertaken within the design and initiate stages, and the management cycle will then involve the delivery and sustain stages occurring in parallel.

The governance themes provide a set of management techniques and constructs to ensure institute activities are adequately planned, controlled and monitored to meet the institute's main objectives as well as stakeholder needs. Associated with the management cycle in the process, there are the outputs from the delivery stage (e.g. research results, awarded degrees and any training that is given) as well as the need to review (e.g. measuring the level of funding secured into the institute, or the number of journal publications or conference papers). Viewing university institutes and centers in terms of an overall cycle, where there are different factors that are of prominence at different stages in the institute's development, has also been advocated by Geisler et al. [16].

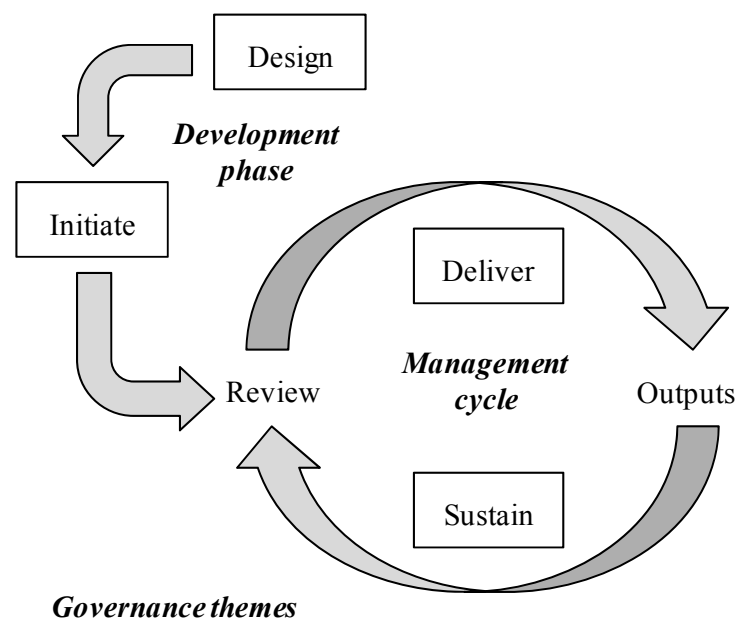

$$
\begin{aligned}
& \text { - Organizational structure } \\
& \text { - Vision } \\
& \text { - Leadership \& stakeholder management } \\
& \text { - Planning \& control mechanisms } \\
& \text { - Business case } \\
& \text { - Generating value for money benefits } \\
& \text { - Risk management } \\
& \text { - Quality management } \\
& \text { - Research \& technology management } \\
& \text { - Commercial management }
\end{aligned}
$$

Fig. 1: Institute management system 
In order to identify some of the key activities and issues that need to be addressed within the four stages, Figure 2 provides an affinity diagram of the institute management system, where the governance themes have been applied to the four stages of the management process. It is suggested that the development and management of multidisciplinary university research institutes will be improved through adoption of the institute management system and by implementation of the processes and structures detailed in the supporting affinity diagram.

In the case of university-industry collaboration, it is further suggested that adoption of an integrated management framework such as the one described will enhance an institute's contribution to the industrial innovation system, through enabling the knowledge generation process and subsequent knowledge acquisition by firms.

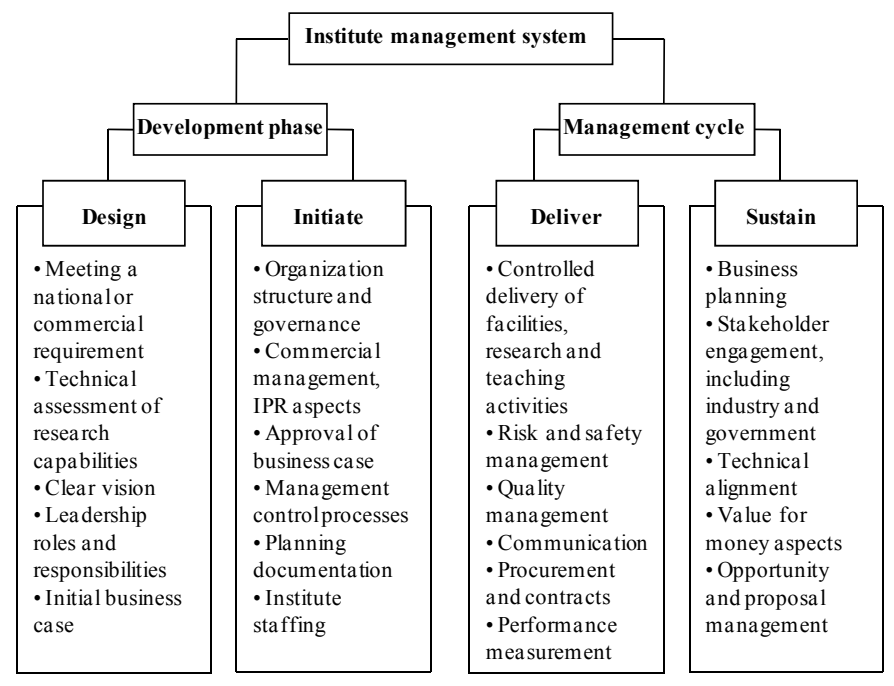

Fig. 2: Affinity diagram for institute management system

\section{Case Study Investigation}

The case study investigation involved application of the institute management system to the development and management of the Institute of Shock Physics (ISP) at Imperial College London in the United Kingdom, which is a university-based institute that undertakes research and teaching in the area of understanding how materials behave under high pressures [17].

The research study involved reflective analysis of the Institute according to the four stages of the process within the institute management system. The Institute was established in 2008, which resulted from a substantial investment by an industrial company through an initial five-year program of funding that will be completed in 2013. In order to provide appropriate background material, Figure 3 shows the organization structure for the Institute and Figure 4 shows a schedule (schematic) of the Institute's five-year program. Finally, Figure 5 provides a top-level view of the Institute's strategy.

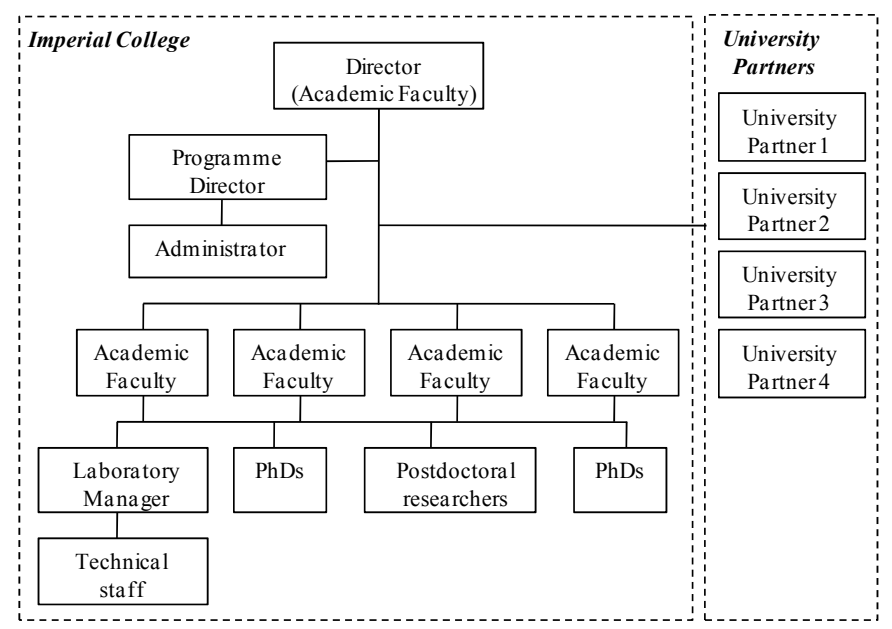

Fig. 3: Institute organization structure

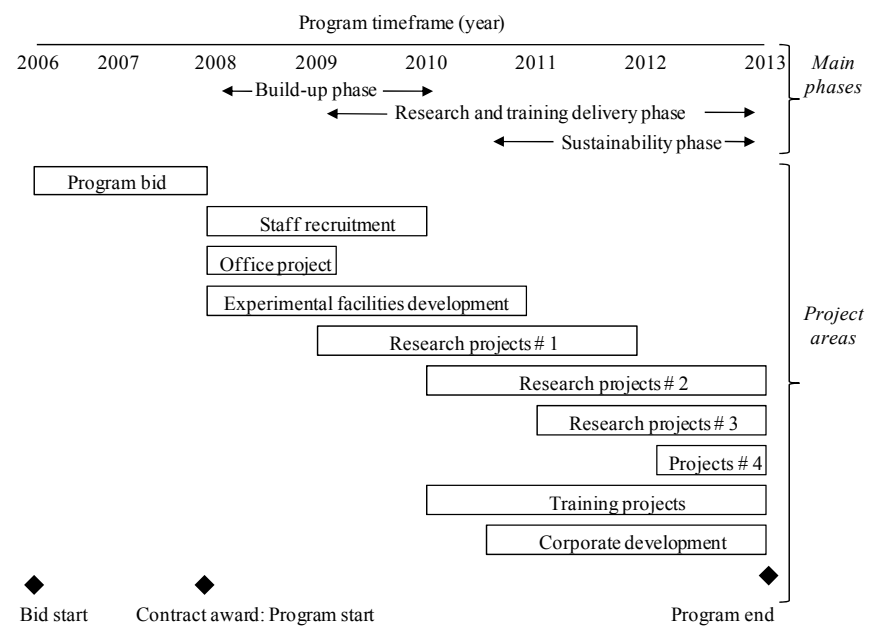

Fig. 4: Institute's schedule for five-year program

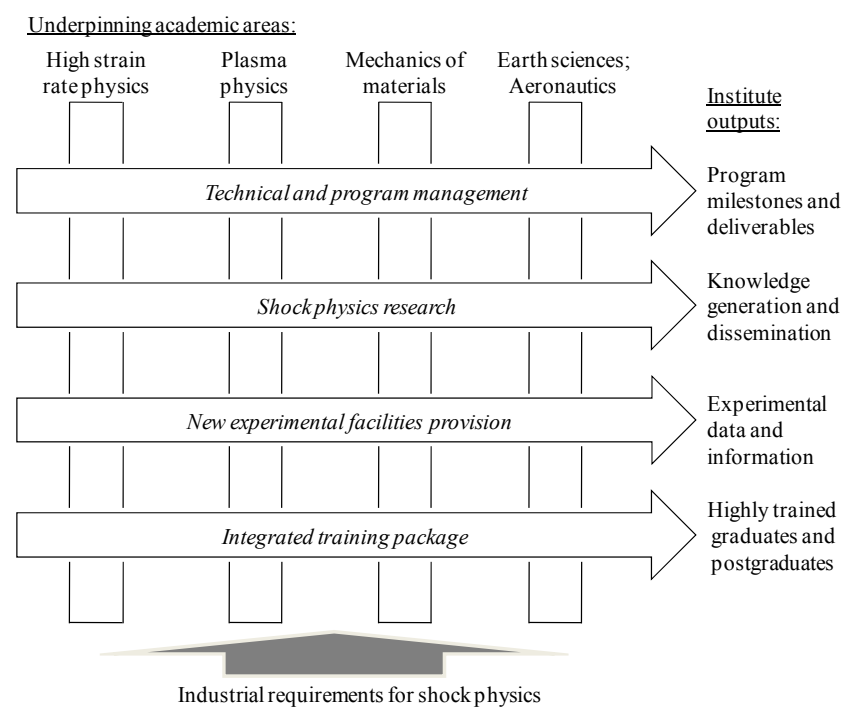

Fig. 5: Institute's top-level strategy 


\section{(i). Design stage}

During the two-year competitive bid phase to secure industrial support of the Institute, from 2006 to 2008, there was significant activity carried out in order to design the Institute so that a leading academic capability in shock physics could be established rapidly. The first part of the design stage involved development of the technical strategy. In order to start this process, a technical audit of research capabilities at the university (Imperial College London) was undertaken. This revealed that there were major strengths in a certain number of underpinning areas within the field of shock physics, such as there being significant capability in pulsed-power driven shocks research. But the audit also revealed there was a lack of capability in static high-pressure research involving diamond anvil cells. Consequently, an early decision was taken to adopt an 'open and inclusive' approach. This eventually led to the Institute building partnerships with four other UK universities, and within Imperial College itself there was involvement by three academic departments. Therefore, the decision to link together seven academic departments across five institutions resulted in the Institute being multidisciplinary from the outset. Across the five universities, the academic departments involved were in the following subject disciplines: Physics, Chemistry, Earth Sciences, Aeronautics and Applied Sciences.

The Institute's reporting and governance arrangements were also carefully designed. There is monthly reporting of activities undertaken across several main areas, namely management, facilities, research, teaching, and corporate development. The monthly reports are distributed to Institute staff and stakeholders from the main university partners and also those from the principal industrial partner. There is also an annual report issued. This level of reporting ensures progress is tracked regularly and it helps the company to demonstrate that key program objectives and milestones are being met. To accompany this reporting regime, the Institute has two management boards. There is an operations board that meets every three months. This board is able to review progress across the Institute and ensure that arising issues can be dealt with promptly, for example, by considering the implications caused from the delay in appointing a member of faculty. The membership of this board includes academic/technical and operations management staff from both Imperial College and the partner company. As a complement to the operations board, the Institute's strategic board meets on an annual basis. The annual report is delivered to this board, which concentrates on considering long-term strategy for the Institute, e.g. opportunities for gaining additional funding and also options for collaborating with overseas organizations.

\section{(ii). Initiate stage}

Once the Institute's structures and processes had been designed, there was a need to initiate the Institute's program of work. Since the establishment of the Institute rested on the ability of the host university, Imperial College, to gain a major industrial contract. Initiation was therefore closely linked to the approval of the Institute's business case, and this involved two parts: a business case to the company for the main program funding, and another business case to Imperial College in order to receive approval for the upgrade of a laboratory to house high-pressure equipment that was needed to deliver a large part of the Institute's research program.

The business case for industrial support was related to the concept of financial leverage, i.e. the level of additional funding that was likely to be achieved and was in addition to that provided by the company. In order to determine this level of additional research funding, the average level of research funding for the different levels of tenured faculty (i.e. lecturer, reader and professor) was calculated. Then, an assessment was made on the expected involvement of the Institute's faculty in the area of shock physics. Finally, an aggregate total was generated based on the expected involvement of faculty and the level of research they would generate according to their grade. This overall figure allowed the company to make a judgment on the "value for money case' for its investment, although the close fit of the academic capability to the scientific requirements of the company was clearly also of overriding importance.

The business case for funding from the university was based on a discounted cash-flow (DCF) calculation. The net present value (NPV) of incomes over the five-year program was calculated using a discount rate (DR) based on the UK borrowing rate at that time plus the marginal cost of borrowing for the university (measured in basis points). The NPV method demonstrated there was a clear positive cashflow expected and so the university was able to justify its investment. Additionally, this financial analysis had to accompany an assessment of the technical and academic strategy for establishing the new Institute in Shock Physics. Consequently, the business case articulated the technical merit of bringing together different disciplines to form the Institute and this included an assessment of the potential industrial applications of the research, e.g. understanding impact damage on spacecraft, aircraft and automobiles as well as meteorite impact studies and understanding the effect of high pressures on materials at the centre of planetary bodies.

A further important part of the initiate stage was the contractual arrangements. The industrial partner was understandably keen to protect its commercial position and so a 'hybrid enabling contract' mechanism was adopted. This contract was structured around the delivery of the five year program but crucially only $60 \%$ of the overall value was attached to the contract from the outset. The remaining $40 \%$ would need to be enabled through the contract on a 'call-off' basis, i.e. tasks placed on a tasking contract. These tasks would have pre-defined firm price costs provided as part of the overall contract and there was a schedule for task placement. However, the decision of when to place the tasks rested with the company and hence there was a significant degree of control of the work program retained by the company. To date, all of the scheduled tasks have been placed by the company. From the perspective of the university, whilst this arrangement was acceptable, it was important that the main contract had a sufficiently high enough financial value attached from the beginning. This so called 'baseline contract' was required in order to underpin 
the business case for university funding of the laboratory development for the new high-pressure equipment.

\section{(iii). Deliver stage}

Following on from signature of the industrial contract, the Institute's integrated research and teaching activities could commence, although in the early part of the program this work was restricted in scope due to the Institute only having a limited number of academic staff. General management activities undertaken in support of the research and teaching work included financial monitoring and cost control; risk management; and project performance measurement. Financial monitoring and cost control was undertaken at the Institute program level, and this ensured the overall financial position of the Institute could be controlled. Budgets for research projects were delegated to the principal investigators (PIs) and this allowed financial management to be decentralized. Additional project budgets, such as those for training projects to manage a new Masters degree in shock physics and projects to carry out short training courses were also delegated to the lead faculty members for the corresponding projects. PIs were responsible for producing technical proposals for the $\mathrm{PhD}$ projects, which were started on a rolling basis throughout the five-year program. Although there was a need for proposals to relate to the overall technical strategy of the Institute, it was nevertheless for the PIs to put forward proposals that were aligned to their own research areas. This 'bottom-up' approach ensured faculty members were confident in the quality of the research proposals and furthermore they felt that the results could potentially be published in academic journals of an appropriate standing.

Risk management was carried out through the use of an Institute risk register that was reviewed on a quarterly basis (every three months). Along with a significant number of smaller risks, there were two major areas of risk identified. These were the financial sustainability of the institute beyond the initial five-year program; and the safety risks associated with a new high-pressure experimental research facility being developed by the Institute. Sustainability is addressed by the next stage in the process. In regards to safety risks, it was decided that the Institute would adopt a system safety engineering approach [18]. This systems based methodology integrated safety management at different levels by considering technical and social factors, and was brought together as part of an Institute 'code of practice' document. Furthermore, the FMEA (failure modes and effects) tool was used to capture and manage risks for the new experimental research facility, and systems architecting was used as diagramming method to structure safety-related data and information. This systems approach proved to be particularly effective since it helped to structure the complex arrangements and decisions that were needed to establish the new laboratory facility and it also helped build up confidence by the university's management in the health and safety approach that was adopted.

In order to ensure effective delivery of the individual research and teaching projects, it was decided to implement a balanced scorecard approach [19] to frame performance measurement across the Institute's program. The scorecard includes detailed metrics according to four main areas, which are financial (1); institute capability (i.e. staff, facilities) (2); training and education (3); and research outputs (publications, presentations, etc) (4). Scorecard reports are generated on a quarterly basis and issued to stakeholders from the university and the partner company, thereby ensuring a regular and broad-based assessment of the Institute's performance is undertaken.

\section{(iv). Sustain stage}

The risk management process described previously identified the long-term sustainability of the Institute's funding as a major area of risk. Clearly the Institute must deliver its current program of research and training projects but there should also be an adequate focus on developing follow-on or additional sources of funding. Consequently and in parallel with delivery, the sustain stage of the process is an attempt to recognize the need for an ongoing focus on corporate development, outreach and externally focused initiatives. Within the Institute and from an early stage, outreach activities were undertaken. This included developing networks of interactions and collaborations with other UK universities and also with overseas scientific organizations that undertook research in the area of shock physics. This is further augmented through an annual conference that is hosted by the Institute and which allows technical specialists in the field to present their work and also crucially provides opportunities for informal networking.

After the first two years of operations, the Institute placed an increasing importance on corporate development, such as meeting with other prospective funders of research including other industrial organizations and UK research funding councils. However, through considering the long-term development of the Institute, it is important for the technical strategy to be aligned with the necessary business planning. Therefore, an assessment has been made of the scope to diversify the funding sources of the Institute through considering different applications for the research. This assessment and the subsequent analysis is an ongoing process that will be used to guide research proposal activity and gradually build up the funding base of the Institute over the medium to long-term. In terms of business planning frameworks that can be used to support corporate development, there are a number of methodologies that are currently under consideration. One such approach is technology roadmapping [20], which is a planning and diagramming technique that can be used to plan the development of technical capabilities over time. The roadmap diagrams that are produced have the advantage that they can summarize the strategy for developing a particular area but the real value in such diagrams is actually derived from the structured planning work that is needed in order to develop the diagrams. For example, through bringing together multidisciplinary teams of experts from across the shock physics areas and including key stakeholders of the Institute as part of structured brainstorming sessions.

Activities to ensure the Institute's funding is placed on a sustainable footing need to occur in parallel with the delivery 
of research and teaching projects but the long-term health of the Institute will equally rest on the strength of networks and social interactions that are built up between Institute staff and the relevant stakeholder community. In this regard and in the case of university-industry collaborations, Philbin [21] has elucidated a number of mechanisms that emphasize the importance of having the requisite social capital in place. For example, the need for open dialogue between staff from the university and those from the collaborating company as well as sufficient levels of trust between both parties so as to facilitate improved research collaborations and ultimately lead to strategic alliances that provide enhanced benefits for the organizations involved.

\section{Analysis of the Case Study Findings}

In order to assess the value of the institute management system for developing and managing academic institutes and to evaluate its effectiveness, an 'analysis lens' has been used as a supporting assessment framework. The methodology employed by Ireland, Hitt and Vaidyanath [22] to examine strategic alliances is appropriate for this application, since it is derived from a broad set of underpinning management frameworks, which are transaction cost economics (TCE) [23], the resource-based view (RBV) of strategy [24], and social network (SN) theory [25]. Consequently, Table 1 provides the results of the analysis according to the four stages within the process against these three management frameworks.

Analysis of the four stages within the process against the three underpinning management frameworks highlighted that adoption of the institute management system can be effective across a broad range of perspectives and there is potential to create value for both the university and partner organization. It is, however, acknowledged that the initial application of the management system has only been undertaken on the development and management of a single academic institute. Consequently, additional studies involving a wider range of university institutes and centers are recommended in order to further evaluate the strengths and weaknesses of this methodology.

Through interpretation of this analysis, it can be seen that the social and relational dimensions of institute activities are particularly important, and especially in regard to the relationships that are forged by an institute's leadership and faculty members. This can be viewed through the concept of boundary spanning [26], where there are certain challenges associated within managing across a boundary, such as a project, organizational or geographical boundary. The ability of an institute's leadership and faculty members to have the requisite skills as well as the motivation to successfully manage and direct beyond their own disciplines, both within the Institute and externally, will therefore have a significant impact on the Institute's performance. Encouraging an open and inclusive culture, such as the one that has been established at the Institute is one mechanism that may promote such boundary spanning.

The other key concept arising from analysis of the case study application is that of absorptive capacity [27], which can be regarded as an organization's ability to acquire and then assimilate knowledge. The research and technology outputs of a university institute are only of value to an industrial sponsor, if the sponsor itself has the capabilities to effectively deploy and utilize the acquired knowledge within its R\&D capability. The company will therefore need to have a critical mass of scientific, technological or engineering staff, supporting organizational processes and crucially a research focused culture if this process is to proceed smoothly. The challenge then for companies that collaborate with university institutes is to ensure that they are prepared and have the capacity to allow this knowledge transfer process to take place.

\begin{tabular}{|c|c|c|c|}
\hline Process stage & TCE & RBV & SN \\
\hline Design & $\begin{array}{l}\text { The design of the Institute } \\
\text { takes account of potential } \\
\text { funding streams, since } \\
\text { without these there will be } \\
\text { no resources to extend the } \\
\text { academic mission. } \\
\text { Establishment of the } \\
\text { Institute design should } \\
\text { also be achievable within } \\
\text { the desired timeframe. }\end{array}$ & $\begin{array}{l}\text { The university should have } \\
\text { the necessary research } \\
\text { capabilities (resources) in } \\
\text { order to build an attractive } \\
\text { proposition for } \\
\text { stakeholders, which } \\
\text { supports the basis for the } \\
\text { Institute. Existing research } \\
\text { areas at the university were } \\
\text { assessed to be of high } \\
\text { quality in order to } \\
\text { contribute to the Institute. }\end{array}$ & $\begin{array}{l}\text { In order for the design } \\
\text { stage to be started there } \\
\text { was a need for a major } \\
\text { external driver in the } \\
\text { form of potential } \\
\text { industrial funding. But } \\
\text { there also needed to be } \\
\text { faculty who had the } \\
\text { necessary networks and } \\
\text { social capital with } \\
\text { stakeholders to realize } \\
\text { the Institute's vision. }\end{array}$ \\
\hline Initiate & $\begin{array}{l}\text { The business case that } \\
\text { was developed and } \\
\text { approved focused on } \\
\text { delivering technical value } \\
\text { but crucially also } \\
\text { contributed financial } \\
\text { benefits for the Institute's } \\
\text { sponsor and also created } \\
\text { funding opportunities for } \\
\text { the university. }\end{array}$ & $\begin{array}{l}\text { The initiation stage and } \\
\text { contractual arrangements } \\
\text { that underpin the Institute } \\
\text { were aligned to the } \\
\text { university's overall } \\
\text { organizational strategy for } \\
\text { engaging with research } \\
\text { sponsors in this area. }\end{array}$ & $\begin{array}{l}\text { Through building on the } \\
\text { design stage, the } \\
\text { Institute's leadership } \\
\text { (both technical and } \\
\text { administrative) were able } \\
\text { to generate enough social } \\
\text { capital within the } \\
\text { university and partner } \\
\text { company for the Institute } \\
\text { to be formally launched. }\end{array}$ \\
\hline Deliver & $\begin{array}{l}\text { Financial management of } \\
\text { the Institute program and } \\
\text { the individual projects } \\
\text { provides support to the } \\
\text { delivery of research and } \\
\text { teaching activities. This } \\
\text { includes cost control and } \\
\text { financial modeling of } \\
\text { expenditures. }\end{array}$ & $\begin{array}{l}\text { In order to deliver the } \\
\text { Institute's program of } \\
\text { research and teaching, there } \\
\text { was the appointment of key } \\
\text { faculty that have a } \\
\text { specialism in the } \\
\text { (multidisciplinary) shock } \\
\text { physics area and this was } \\
\text { considered in regards to } \\
\text { departmental recruitment } \\
\text { strategies. }\end{array}$ & $\begin{array}{l}\text { Principal investigators } \\
\text { for research projects } \\
\text { undertaken within the } \\
\text { Institute needed to have } \\
\text { good working } \\
\text { relationships with the } \\
\text { research sponsors in } \\
\text { order to ensure the } \\
\text { scientific requirements } \\
\text { can be delivered. }\end{array}$ \\
\hline Sustain & $\begin{array}{l}\text { Long-term development } \\
\text { of the Institute's } \\
\text { capabilities rests on the } \\
\text { ability to attract } \\
\text { investment into the } \\
\text { Institute. Companies will } \\
\text { be concerned with value } \\
\text { for money assessment of } \\
\text { research expenditures. }\end{array}$ & $\begin{array}{l}\text { The ability to sustain the } \\
\text { Institute beyond its initial } \\
\text { program will need to be } \\
\text { developed alongside the } \\
\text { university's strategy for } \\
\text { research and this will need } \\
\text { to involve the continued } \\
\text { support of senior faculty } \\
\text { and university leadership. }\end{array}$ & $\begin{array}{l}\text { Building a series of } \\
\text { collaborative networks, } \\
\text { both within the main } \\
\text { university and also with } \\
\text { partner universities and } \\
\text { industrial companies, } \\
\text { will help position the } \\
\text { Institute for continued } \\
\text { investment. }\end{array}$ \\
\hline
\end{tabular}

Table 1: Analysis of the four stage process

\section{Conclusions}

The paper has provided a discussion of the merits of multidisciplinary university research institutes. This has included a literature review, highlighting the value that can be derived by both universities and sponsors, such as industrial companies, from participating in such initiatives. The ability to bring together faculty and to establish a new university institute requires a major stimulus. This is likely to be in the form of an emerging scientific or technological requirement for research or teaching in a multidisciplinary area, and which will need to be achievable through funding from a government agency, industrial company or philanthropic source. 
Ensuring that a new university institute becomes embedded within the existing university structures and concomitantly delivering the academic outputs required by the sponsors can be a significant challenge for an institute's leadership. Moreover, from the perspective of sponsors such as those from industry, there will be issues and challenges in ensuring the academic institute produces the knowledge outputs that can add value to products or services produced by the company. If the research undertaken by the institute is not adequately targeted to meet the industrial requirements then it may not add sufficient value to the company's R\&D capabilities. Conversely and from the university perspective, if the research outputs are not of the required intellectual or academic quality, then there may be difficulties in publishing research results in the desired academic journals. It can therefore be observed that there can be competing demands on university institutes, which result in the need for institute's to have robust and durable management processes and supporting structures. It is in this context and through building on work in the literature that the institute management system has been proposed.

The case study investigation revealed that pursuing the activities provided by the institute management system can provide a firm foundation for the establishment of a new university institute. Furthermore, this methodology provides a systematic approach to ensure stakeholder needs are met and there are clear structures and processes in place to deliver the research and teaching, and ultimately contribute to the institute's long-term sustainability. Moreover, analysis of the four stages within the process according to the TCE, RBV and SN management frameworks has highlighted the broad basis for the methodology and its applicability to add value and improve the science and technology management process.

Considering the performance of university institutes from an industrial perspective needs to include an assessment of the absorptive capacity of the enterprise, since the ability of any company to acquire knowledge generated by a university institute will be directly related to the value returned to the company's R\&D capability. Companies will need to consider if they have a supporting culture and awareness by staff of the merit in utilizing research results and knowledge gained from collaborations with academic institutes. Conversely, leadership staff and faculty within academic institutes need to be comfortable in boundary spanning across disciplines and also across organizational interfaces. Faculty need to build up a deep awareness of industrial drivers for research if longterm and sustainable collaborations are to be developed. In the case of multidisciplinary research institutes, the institute management system has been proposed and evaluated as a mechanism to help both universities and industrial partners to work together on difficult and challenging technological problems areas that draw on different scientific areas and which meet a determined industrial need.

In terms of specific guidance for industry arising from this research, the following recommendations are made for companies seeking to enhance or initiate new relations with university research institutes:

- Companies should seek to provide universities with clear industrial requirements for research and technology, so that scientific studies can be readily linked to the application area. However, this should not be orientated to restrict the creative knowledge discovery process but more to underscore the industrial relevance of research.

- Companies may benefit from appointing a single institute liaison manager, who can co-ordinate interactions with the institute and ensure consistency in decisions involving both collaborating partners. The manager can also act as an 'ambassador' for the institute within the company, thereby promoting interactions with the university.

- In terms of social capital, it is recommended that companies develop interactions at multiple levels with university institutes, e.g. staff from commercial \& legal; technical; and senior management within the company can interact with their equivalents in the university. This 'ladder of engagement' can significantly strengthen interactions and result in enhanced benefits for both parties.

- An ability to ensure contractual arrangements are 'fit-forpurpose' will likely improve arrangements for companies. Clearly allocation of IP (intellectual property) can be very important, and so university institutes and companies need to adopt consultative and flexible approaches where possible so as to ensure IP negotiations move ahead smoothly.

- Adoption of research outputs from university institutes will likely benefit from companies having a supporting knowledge management system to contribute to new product or service development; which is related to the absorptive capacity of the company.

- Where university institutes are undertaking fundamental research, there will need to be a sufficiently long-term horizon applied to development of any research outputs towards industrial applications. Conversely, supporting more applied research, such technology demonstrator programs, can be more readily linked to new product development.

The drawback of the study reported in this paper is that only a single application of the institute management system has been undertaken and that interpretation of the application may be subject to a normative perspective. However, the conceptual process model proposed clearly builds on a range of supporting studies, and there is a distinct rationale and logical sequence to the model derived from the literature review. Furthermore, preliminary analysis of the case study findings provides additional evaluation of the case study investigation. Future work is suggested on application of the institute management system to a range of different university institutes and centers. Also, it would be useful to explore the interface between the institute management system and the wider innovation systems operated within industrial companies, as this would allow an integrated universityindustry management framework to be developed.

\section{Acknowledgments}

The author would like to thank the support of colleagues within the Institute of Shock Physics and in particular Professor Steven Rose for encouraging these studies. 


\section{References}

1. Haythornthwaite, C., "Learning and knowledge networks in interdisciplinary collaborations," Journal of the American Society for Information Science and Technology, Vol. 57, No. 8 (2006), pp. 1079-1092.

2. Bozeman, B. \& Boardman, P. C., Managing the new multipurpose, multidiscipline university research centers: Institutional innovation in the academic community, IBM Center for the Business of Government: Transforming Organizations Series (2003).

3. Chesbrough, H., Open Innovation, Harvard Business School Press (Harvard, 2003).

4. Cohen, W. M. \& Levinthal, D. A., "Absorptive capacity: a new perspective on learning and innovation," Administrative Science Quarterly, Vol. 35, No. 1 (1990), pp. 128-152.

5. Speier, C. \& Palmer, J., "Creating and Sustaining a University Affiliated Research Center: The Center for MIS Studies at the University of Oklahoma," International Journal of Information Management, Vol. 18, No. 6 (1998), pp. 457-459.

6. Van Horne, C., Poulin, D. \& Frayret, J.-M., "Measuring value in the innovation processes of university-industry research centres," International Journal of Technology, Policy and Management, Vol. 10, No. 1-2 (2010), pp. 116-136.

7. Santoro, C. \& Chakrabarti, A. K., "Corporate Strategic Objectives for Establishing Relationships with University Research Centers," IEEE Transactions on Engineering Management, Vol. 48, No. 2 (2001), pp. 157-163.

8. Liyanage, S. \& Mitchell, H. "Organizational Management in Australian Cooperative Research Centers," Technology Analysis \& Strategic Management, Vol. 5, No. 1 (1993), pp. 3-14.

9. Imrie, R. "The Knowledge Business in Academic Planning Research" in Ethics and Planning Research, Eds: Lo Piccolo, F. \& Huw Thomas, H., Ashgate Publishing Limited (2009).

10. Siegel, D. S., Waldman, D. A., Atwater, L. E. \& Link, A. N., "Commercial knowledge transfers from universities to firms: Improving the effectiveness of university-industry collaboration," Journal of High Technology Management Research, Vol. 14, Issue 1 (2003), pp. 111-133.

11. Young, B., Hewitt-Dundas, N. \& Roper, S., "Intellectual property management in publicly funded $R \& D$ centres $-A$ comparison of university-based and company-based research centres," Technovation, Vol. 28, Issue 8 (2008), pp. 473-484.

12. Youtie, J. \& Corley, E., "Federally sponsored multidisciplinary research centers: Learning, evaluation, and vicious circles," Evaluation and Program Planning, Vol. 34, Issue 1 (2011), pp. 13-20.

13. Boardman, P. C., "Government centrality to universityindustry interactions: University research centers and the industry involvement of academic researchers," Research Policy, Vol. 38, Issue 10 (2009), pp. 1505-1516.

14. Lee, K.-J., Tomohiro, O. \& Kazuhiko, K., "Formal boundary spanning by industry liaison offices and the changing pattern of university-industry cooperative research: the case of the University of Tokyo," Technology Analysis \& Strategic Management, Vol. 22, Issue 2 (2010), pp. 189-206.

15. Feller, I, Ailes C. P. \& Roessner, J. D., "Impacts of research universities on technological innovation in industry: evidence from engineering research centers," Research Policy, Vol. 31, No. 3 (2002), pp. 457-474.

16. Geisler, E., Furino, A. \& Kiresuk, T. J., "Factors in the Success or Failure of Industry-University Cooperative Research Centers," Interfaces, Vol. 20, No. 6 (1990), pp. 99-109.

17. Isbell, W. M., Shock Waves: Measuring the Dynamic Response of Materials, Imperial College Press (2005).

18. Philbin, S. P., "Developing an Integrated Approach to System Safety Engineering," Engineering Management Journal, Vol. 22, No. 2 (2010), pp. 56-67.

19. Kaplan, R. S. \& Norton, D. P., "Using the Balanced Scorecard as a Strategic Management System," Harvard Business Review, Vol. 74, No. 1, (1996) pp. 75-85.

20. Phaal, R., Farrukh, C. J. P. \& Probert, D. R., “Technology roadmapping - A planning framework for evaluation and revolution," Technological Forecasting and Social Change, Vol. 71, Issue 1-2 (2004), pp. 5-26.

21. Philbin, S. P., "Developing and Managing UniversityIndustry Research Collaborations through a Process Methodology/Industrial Sector Approach", Journal of Research Administration, Vol. 41, No. 3 (2010), pp. 5168.

22. Ireland, R. D., Hitt, M. A. \& Vaidyanath, D., “Alliance management as a source of competitive advantage," Journal of Management, Vol. 28, No. 3 (2002), pp. 413446.

23. Pessali, H. F., "Metaphors of Transaction Cost Economics," Review of Social Economy, Vol. 67, No. 3 (2009), pp. 313-328.

24. Grant, R. M., Contemporary Strategy Analysis (third edn.), Oxford, Blackwell (1998).

25. Gulati, R., "Network location and learning: The influence of network resources and firm capabilities on alliance formation," Strategic Management Journal, Vol. 20, No. 5 (1999), pp. 397-420.

26. Ratcheva, V., "Integrating diverse knowledge through boundary spanning processes - The case of multidisciplinary project teams," International Journal of Project Management, Vol. 27, Issue 3 (2009), pp. 206215.

27. Gann, D., "Putting academic ideas into practice: Technological progress and the absorptive capacity of construction organizations," Construction Management and Economics, Vol. 19, Issue 3 (2001), pp. 321-330. 